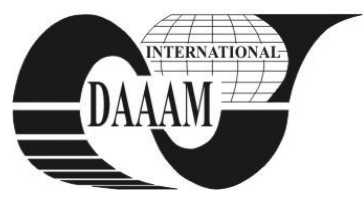

Annals of DAAAM for 2011 \& Proceedings of the 22nd International DAAAM Symposium, Volume 22, No. 1, ISSN 1726-9679 ISBN 978-3-901509-83-4, Editor B. Katalinic, Published by DAAAM International, Vienna, Austria, EU, 2011 Make Harmony between Technology and Nature, and Your Mind will Fly Free as a Bird Annals \& Proceedings of DAAAM International 2011

\title{
POSSIBLE PROTECTIONS OF EMBEDED SYSTEMS INPUTS
}

\author{
OTAHAL, J[iri] \& HRUSKA, F[rantisek]
}

\begin{abstract}
The paper describes the solution for the protection of inputs and outputs of embedded systems. These are the problems of galvanic separation, restrictions disturbing voltage, limit reduction of signals and signal verification of loaded value. They dealt galvanic isolators

and limiters limit on another principle. The work compares different methods of input and output. Another part is a summary of methods for operations related to the evaluation of the accuracy of the capture inputs before further processing. It assessed the speed of operations, accuracy, uncertainty in relation to the type of inputs and their static and dynamic characteristics. The entire content is part of the solution and study embedded systems..

Other parts of the thesis is a mathematical description of the behavior of protection of inputs and outputs. Will be used to find the causes of nonlinearity limit limiters and analog galvanic isolators. The linear optocouplers are designed to the partial non-linearity caused by the method used and participation components.
\end{abstract}

Key words: embedded systems, galvanic separation, linear optocoupler, Strej identification method

\section{INTRODUCTION}

Digital and analog inputs of embeded systems are very sensitive to power surges. The normal maximum repeatable value of the input voltage is 1.1 times the microprocessor supply voltage max. Both because of interference, so the possibility of error when connecting, for example, affixing a higher level of voltage, these inputs must protect against this surge. This thesis analyzes three possible possibilities of surge protection in the tens of volts.

Circuits used:

1. Circuit with a linear optocoupler IL300

2. The TL431 circuit designed to behave as an ideal zener diode. Circuit was set to $2.95 \mathrm{~V}$ output voltage

3. Zener diode circuit for comparison with TL431 *

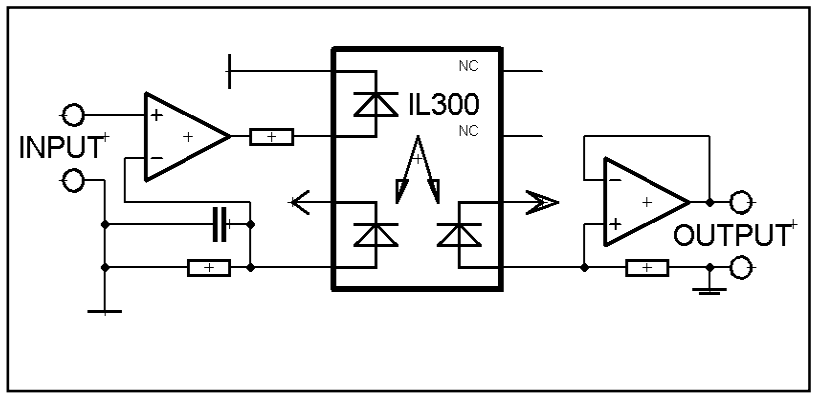

Fig. 1. Schematic circuit used with optocoupler

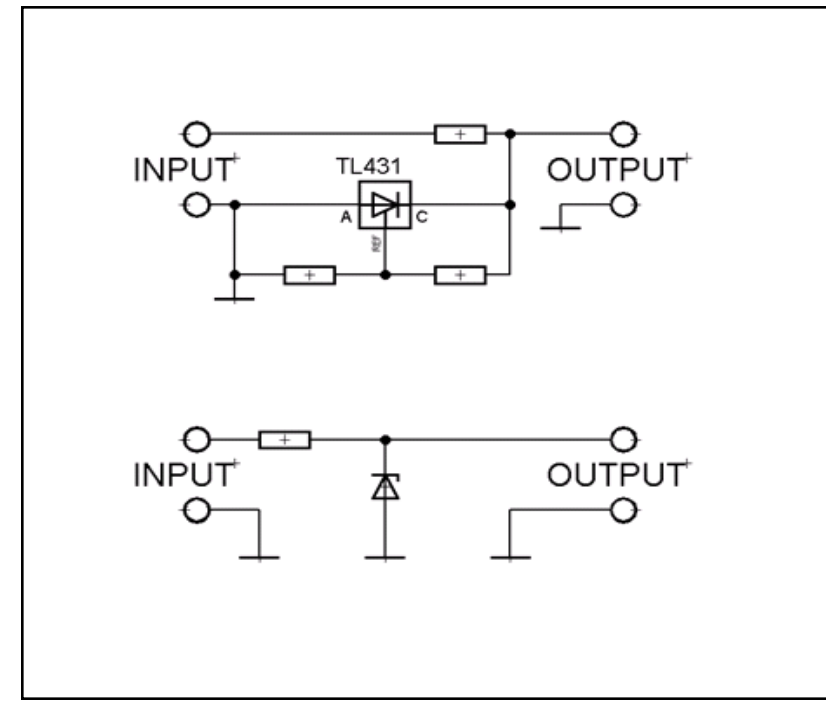

Fig. 2. Schematic circuit used: b) with the TL431 circuit, c) with the Zener diode

\section{TYPE OF MEASUREMENT}

It was measured input / output characteristics of the circuit. Measurements were carried out using the following equipment and software using VEE Pro 9.0, which established a program for this measurement. The input voltage was chosen in the range of 0 to $6 \mathrm{~V}$. Step input voltage was $10 \mathrm{mV}$. Waiting time between samples was chosen as $0.2 \mathrm{~s}$ were sufficient to fully stabilize the input voltage. Supply voltage of both the power supply circuit IL300 was 5.01 V. Measurements were repeated 10 times for each input voltage from 0 to $6 \mathrm{~V}$. Circuit with the TL431 was set to limit voltage $2.95 \mathrm{~V}$. Zener diode according to the manufacturer for voltage $3 \mathrm{~V}$.

\section{USED EQUIPMENT}

- Programmable input voltage source Agilent $3632 \mathrm{E}$

- Voltmeter "A" Agilent 34410A to measure the output voltage Circuit with IL300

- Voltmeter "B" Agilent 34410A to measure the output voltage Circuit TL431

- Voltmeter "C" Agilent 34410A to measure the output voltage Circuit with Zener diode

- Agilent 34410A voltmeter to measure the input voltage circuit - Multimeters Agilent 34410A were connected to a computer via USB

- Agilent E3632A Programmable source was connected to a computer via GPIB and GPIB converter / USB * 


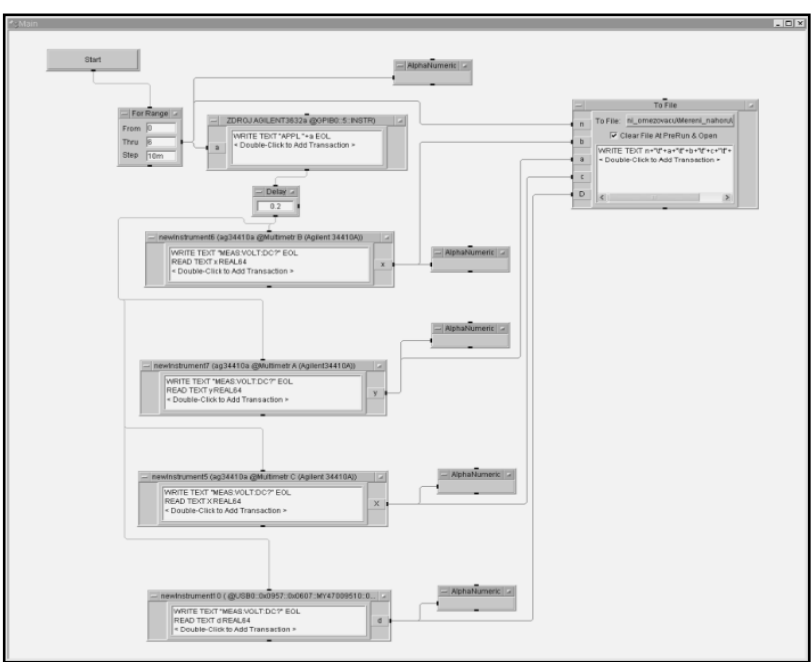

Fig. 3. Program in VEE Pro 9.0 for automatic measurement

\section{MEASURE EVALUATION}

Circuit with a linear optocoupler IL300:

The resulting characteristics show several nonlinearities (area "A", "B") and the resulting deviation from the input voltage is determined by the increased gain of operational amplifiers, which can remove the appropriate circuit connection. R3 was set from $30 \mathrm{k} \Omega$ to $21.8 \mathrm{k} \Omega$

Circuit to circuit TL431:

The resulting highly linear characteristic and the resulting deviation from the input voltage

(Area ' $\mathrm{C}$ ') are caused by from their consumption of the circuit and current through resistors R5 and R6.

Zener diode circuit:

As evident from the chart below, the Zener diode circuit has poor properties and it is listed here only for a comparison.

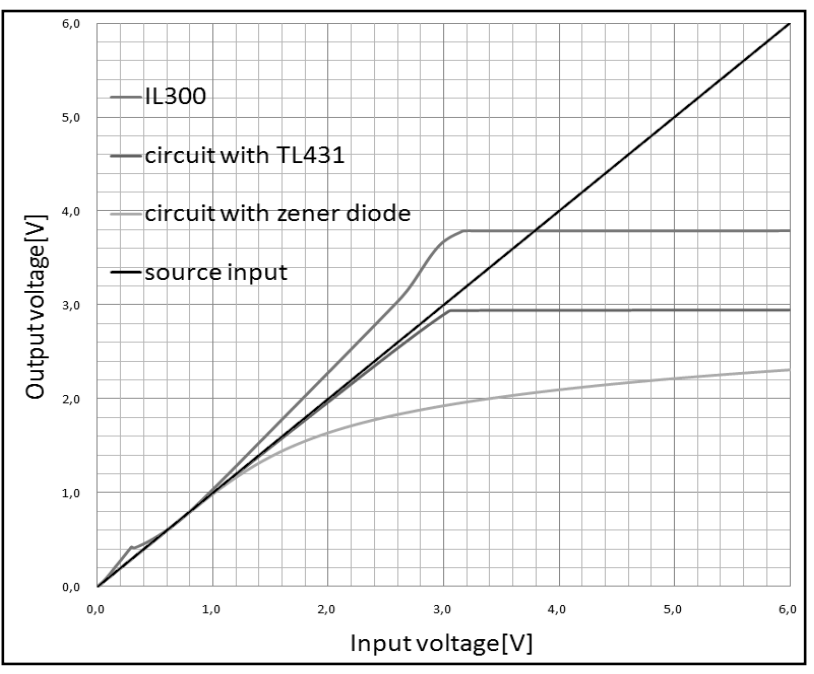

Fig. 4. Input / Output characteristics of measured circuit

It was searched for the cause of nonlinearities. it was measured input / output dynamic characteristics. The testing input signal was used the square wave signal. The testing signal frequency was $20 \mathrm{kHz}$ and the duty cycle was $50 \%$.

As can be seen in Fig. 5, there was a very high oscillation. It doesn't make any differences if amplitude or frequency of the input signal was changed. Same oscillation on the same amplitude and frequency is also when the DC invariable input was used. The oscillation frequency was $178.6 \mathrm{kHz}$ and the amplitude was $1.49 \mathrm{~V}$. When $1 \mathrm{nF}$ capacitor was added to the input operational amplifier negative feedback, the oscillation was removed.

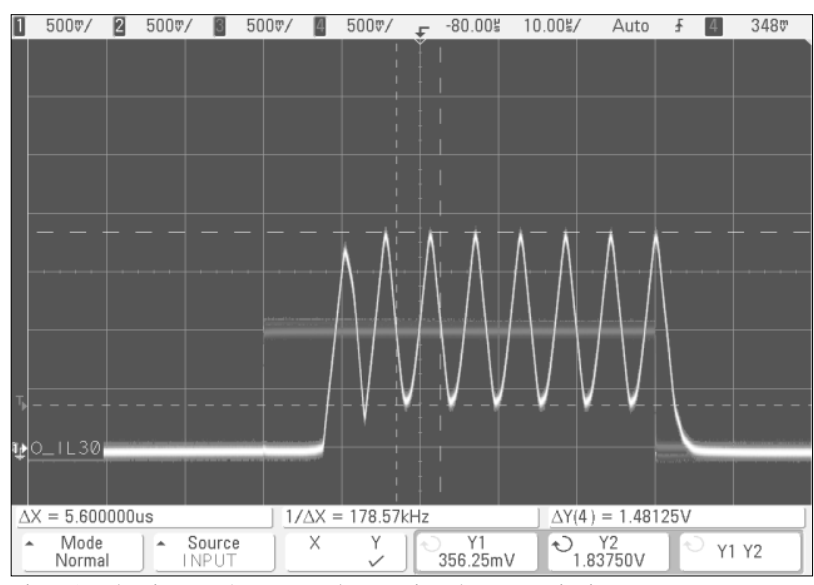

Fig. 5. The input / output dynamic characteristic

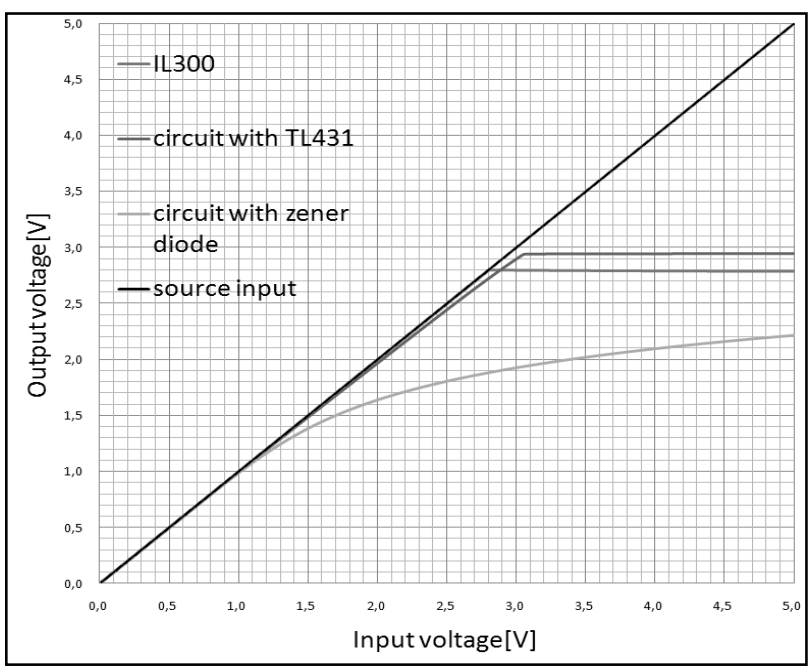

Fig. 6. The static input / output characteristic after the intervention to circuit

Figure 8 shows the static input / output characteristic after the intervention to circuit. It is evident from figure hereinbefore output signal from circuit with IL300 strictly imitates that of input signal from generator

\section{CONCLUSION}

Another part of the work in the next period is a mathematical description of the behavior of protection of inputs and outputs. Will be used to find the causes of nonlinearity limit limiters and analog galvanic isolators.

\section{ACKNOWLEDGEMENTS}

This work was supported in part by the Ministry of Education of the Czech Republic under grant MSM 7088352101 and in part by Tomas Bata University in Zlin under grant IGA/32/FAI/11/D and and by the European Regional Development Fund under the project CEBIA-Tech No.CZ.1.05/2.1.00/03.0089.

\section{REFERENCES}

Otáhal, J, et al. (2011). Protections of embedded systems inputs. In OTÁHAL, Jiří. Proceedings of 13th WSEAS International Conference on AUTOMATIC CONTROL, MODELLING \& SIMULATION (ACMOS '11). Otáhal J. (Ed.), pp. 407-411

Corriou, J. (2004). Process control: Theory and applications. Springler, ISBN 1852337761, USA 